\title{
A INFLUÊNCIA DO PASSADO HISTÓRICO COLONIAL NO RACISMO CONTRA OS AFRICANOS E AFRODESCENDENTES EM PORTUGAL
}

\author{
THE INFLUENCE OF THE COLONIAL HISTORICAL PAST ON RACISM AGAINST \\ AFRICANS AND AFRO-DESCENDANTS IN PORTUGAL
}

\author{
Nelsio Gomes Correia ${ }^{1}$
}

RESUMO: O presente artigo trata da influência do passado histórico colonial no racismo contra os africanos e afrodescendentes em Portugal. Nesta lógica, ressalta que a grande maioria dos imigrantes que na atualidade compõem este povo africano na diáspora, particularmente em diferentes bairros de Lisboa, vieram dos países africanos colonizados por Portugal após a emancipação desses territórios dominados pela política imperialista. Assim sendo, o estudo objetiva-se em compreender as implicações do racismo sofrido pelos africanos e afrodescendentes em Portugal. Em vista disso, é observado que existe um problema complexo do reconhecimento das populações africanas que residem fora dos seus países de origem, então isso requer o conhecimento profundo da história e dos acontecimentos do passado colonial em África e que determinaram todo este processo de imigração forçada desta população para diversos países do mundo e das suas trajetórias e lutas até nos dias de hoje. Em relação ao percurso metodológico do trabalho, foi assentado numa pesquisa bibliográfica de abordagem reflexiva em que os dados extraídos dos livros e artigos de diferentes pesquisadores recebem tratamento interpretativo dos temas discutidos e relacionados ao assunto desenvolvido aqui no nosso trabalho. Em suma, o racismo deixa os africanos e as pessoas de ascendência africana em Portugal muito vulneráveis, incluindo danos morais e psicológicos. Além disso, é averiguado como um projeto político criado pelos Estados modernos para estabelecer a segregação racial e hierarquizando os distintos grupos sociais com culturas desiguais.

Palavras-chave: Portugal. Bairros periféricos. Violência policial. Discriminação racial. População negra.

ABSTRACT: This article deals with the influence of the colonial historical past on racism against Africans and Afro-descendants in the neighborhoods of Lisbon. In this logic, it emphasizes that the vast majority of immigrants who currently make up this African people in the diaspora, particularly in different neighborhoods of Lisbon/Portugal, came from African countries colonized by Portugal after the emancipation of these territories dominated by imperialist policy. Therefore, the study aims to understand the implications of racism suffered by Africans and Afro-descendants in different neighborhoods of Lisbon. In view of this, it is observed that there is a complex problem of recognition of African populations residing outside their countries of origin, so this requires a deep knowledge of the history and events of the colonial past in Africa and that determined this entire process of forced immigration. Of this population to different countries of the world and of their trajectories and struggles until today. Regarding the methodological course of the work, it was based on a bibliographical research with a reflective approach in which the data extracted from books and articles by different researchers receive an interpretative treatment of the topics discussed and related to the subject developed here in our work. In short, racism leaves Africans and Afrodescendants in Lisbon very vulnerable, including moral and psychological damage. In addition, it is investigated as a political project created by modern States to establish racial segregation and hierarchizing the different social groups with unequal cultures.

Keywords: Portugal. Peripheral neighborhoods. Police violence. Racial discrimination. Black population.

\footnotetext{
${ }^{\mathrm{I}}$ Bacharelado Interdisciplinar em Humanidades e licenciando em Sociologia pela Universidade da Integração Internacional da Lusofonia Afro-brasileira - UNILAB. Instituto de Humanidades - IH. Atualmente estou cursando Mestrado em Estudos Africanos no ISCTE-IUL em Lisboa/Portugal.Pesquisa as temáticas relacionadas aos Direitos Humanos, Poder Judiciário, Democracia, Cooperação Internacional Norte-Sul e Gênero na África. E-mail: gomesnelsio@gmail.com.
} 


\section{INTRODUÇÃO}

Neste artigo, discutimos acerca da influência do passado histórico colonial no racismo contra os africanos e afrodescendentes em Portugal. Uma vez que hoje em dia é observada que há vestígios coloniais presentes nas relações raciais em todos os países em que houve a miscigenação e também aqueles que possuem um passado inerente a escravidão e são, até então, estruturalmente racistas mas que não se admitem apresentar que são, contudo as suas políticas e nos programas dá para entender e a relação dos povos nativos desses países com as pessoas negras consegue perceber que ainda permanece o legado colonial na mente e na sociedade.

Em vista disso, o presente artigo tem como objetivo compreender as implicações do racismo sofrido pelos africanos e afrodescendentes em Portugal.

Assente noutra concepção, é entendida que os privilégios que os brancos europeus têm através do passado histórico colonial, continua fortalecendo a discriminação racial contra a população afrodescendentes e os imigrantes africanos na diáspora, sobretudo em diferentes bairros periféricos de Lisboa. Nessa conjuntura, é notável que a violência policial é instigada pelo preconceito racial em Portugal, também responsável pela diabolização e o menosprezo das práticas culturais, artes, costumes e a produção dos saberes endógenos por africanos e afrodescendentes na sociedade portuguesa.

Em relação ao percurso metodológico do trabalho, foi assentado numa pesquisa bibliográfica de abordagem reflexiva em que os dados extraídos dos livros e artigos de diferentes pesquisadores recebem tratamento interpretativo dos temas discutidos e relacionados ao assunto desenvolvido aqui no nosso estudo.

A ideia do pertencimento da diáspora tem conexão com a experiências diaspóricas ligadas ao pertencimento das distintas identidades culturais presentes na Europa e nas Américas. Reinventar novas práticas culturais na diáspora é uma nova forma de resistência contra a invisibilidade das identidades das pessoas negras na diáspora. Nos momentos atuais é muito forte a discussão sobre a questão da superioridade racial na qual é visível a continuidade da ideia de que o homem branco europeu é superior ao negro/preto. Mas no início, o conceito não era usado para classificação dos seres humanos, dado que:

Etmologicamente, o conceito de raça veio do italiano razza, que por sua vez veio do latim ratio, que significa sorte, categoria, espécie. Na história das ciências naturais, o conceito de raça foi primeiramente usado na Zoologia e na Botânica 
para classificar as espécies animais e vegetais [...]. Como a maioria dos conceitos, o de raça tem seu campo semântico e uma dimensão temporal e especial. No latim medieval, o conceito de raça passou a designar a descendência, a linhagem, ou seja, um grupo de pessoa que têm um ancestral comum e que, ipso facto, possuem algumas características físicas em comum (MUNANGA, 2004, p. I).

Vale evidenciar que o conceito de raça que agora é colocada em discussão contemporaneamente e utilizada para comparar grupos de indivíduos que possuem a mesma tonalidade de pele, inicialmente era aplicada para classificar as espécies de animais e vegetais e não caracterizar as pessoas que têm a mesma descendência. Por um lado, a ideia de raça tornou-se sinônimo de Nação no final do século XIX, ou seja, passou a adquirir o sentido de Nação a partir do fim deste mesmo século.

Para Almeida (2019), "a sociedade contemporânea não pode ser compreendida sem os conceitos de raça e de racismo". Assim sendo é óbvio que o racismo é sempre estrutural uma vez que faz parte das nossas relações sociais, ou seja, abrange a organização económica, institucional, política, social e assim por diante. O forte racismo dá a essência, a concepção da superioridade e inferioridade racial reproduzida cotidianamente e que continua sendo responsável pela segregação social e a tecnologia que fortalece a reprodução das variadas formas desigualdades étnico-raciais e a violência que marcam a vida na sociedade moderna.

Perante essa circunstância, é notório a presença das manifestações do racismo cotidiano nas relações interpessoais, assim como nas movimentações das instituições públicas e privadas, são exteriorizações de ações mais profundas e que estão continuamente progredindo nas determinações políticas e econômicas vivenciadas na sociedade em diferentes contextos. A noção de raça hoje surge para possibilitar a classificação de distintos seres humanos é visto como um fenômeno da modernidade desde meados do século XVI. O termo raça não é improgressivo e estagnado, a sua essência está ligada às situações históricas em que é posta.

Nos dias atuais, em particular na diáspora, verifica-se várias ondas de violências xenofóbicas, gênero e de racismo enraizado. A partir deste pressuposto é urgente e necessário pensarmos nessas circunstâncias ameaçadoras das pessoas negras, dado que é observada várias ondas de rejeição da diversidade cultural étnica para favorecer a permanência das hierarquias culturais, diante disso, se percebe que estamos a vivenciar as 
repercussões da violência colonial fundamentada nas discriminações raciais também no Brasil e os conflitos xenófobos na África do Sul (MENESES, 2016).

Nesta mesma lógica, partindo de uma análise crítica das diferentes formas de violências xenofóbicas, gêneros e o racismo arraigado que a comunidade negra vivencia na diáspora. Desta forma, é observada que há grandes desafios acerca do não reconhecimento desta ampla diversidade cultural e étnica existente no âmbito Sul global e epistêmica, isso por outro lado permite compreender de forma genérica os desafios das raízes das desigualdades sociais existente no mundo que está a ameaçar a cidadania e os sentimentos de pertença.

O racismo sofrido pelo negro desde a invasão colonial em África deixa o mesmo sem alternativas e acaba por pensar que a assimilação dos valores culturais dos brancos é a única forma de sair da condição de inferioridade em que se encontra, posto isto Kabengele diz que:

\footnotetext{
Através de uma literatura pseudocientífica produzida dentro da ideologia colonial, o negro instruído na escola do colonizador toma pouco a pouco conhecimento da inferioridade forjada pelo branco. Sua consciência entra em crise. Graças a uma série de mecanismos de pressão psicológica e outras astúcias, sua alienação deixa de ser teórica. Ele se convence de que o único remédio para curar sua inferioridade, a salvação, estaria na assimilação dos valores culturais do branco superpotente. Essa fase de absorção do branco pelo negro é chamada de embranquecimento cultural (MUNANGA, 1988, p. 5).
}

Perante o exposto, é averiguada que os intelectuais negros fizeram muitos esforços para aprender as línguas ocidentais e além de estudarem as mesmas disciplinas científicas das universidades europeias com os brancos para esperarem um tratamento de igual forma sem discriminação, porém, não foi bem assim, porque percebiam que o domínio das línguas e do conhecimento adquirido de forma idêntica nas academias ocidentais não seriam inferiorizados pelos brancos, mas não foi isso que aconteceu, visto que no espaço social continuam como negros, sendo inferiorizados. Para sair nessa negação, o negro intelectual resolveu voltar suas raízes e rejeitar o embranquecimento. Esse retorno que é dito negritude.

\section{A violência policial como manifestação do racismo contra africanos e afrodescendentes}

A criminalização das pessoas que vivem nos bairros periféricos que são maioritariamente afrodescendentes e imigrantes africanos de múltiplas nacionalidades e 
identidades étnicas oriundas de distintos países africanos colonizados por Portugal e não apenas, vivenciam a rejeição do direito da obtenção à nacionalidade através de vários processos burocráticos desnecessários e envolvendo a violência policial contra os jovens negros residentes nesses bairros autoconstruídos em Lisboa.

O discurso sobre a raça hoje em dia na sociedade portuguesa acaba invisibilizando as atrocidades que aconteceram na África durante a colonização e as narrativas que incentivam o racismo e o ódio contra as populações africanas incluindo a brutalidade policial constante contra um grupo de negros da Cova da Moura o que gerou muitas repercussões na mídia e chamou muita atenção sobre como tem estado a crescer ataques de violências assentadas na raça e xenofobias sem esquecer do racismo institucional ininterrupto vigente na sociedade portuguesa.

No entanto, a "racialização e criminalização do território, brutalidade policial e racismo institucional" são um dos processos responsáveis que marcaram esses acontecimentos de discriminação racial contra a comunidade negra em diferentes bairros periféricos de Lisboa. É evidente que nessa situação se percebe que existe a naturalização da opressão e da regulação dos corpos racializados e inferiorizados, em consequência disso, revela a reprodução das exclusões racistas sofridas pelos negros cotidianamente na sociedade portuguesa (RAPOSO, ALVES et al., 2019).

Se na contemporaneidade continua acontecendo as violências reforçadas pelo ódio de caráter racial em muitos países e especialmente em Portugal, pode ser entendida que é o resultado da negação da existência do racismo e falta de interesse em desmantelar o mesmo. Essa problemática vigente mostra que este país ainda está ligado com os vestígios coloniais que pode-nos levar a concluir que há uma naturalização da violência policial contra a população negra em Lisboa. Ao voltar a época passada durante a colonização em África, o próprio colonizador colocava o colonizado na condição de servidão e considerado como um inferior.

A invisibilização que a população negra passa neste país está conectada com a história da escravidão que esse povo sofreu e contribuiu na construção desta nação. Outros problemas enfrentados é o acesso à habitação que não é fácil adquirir e por esse motivo que muitas pessoas negras residem em bairros periféricos de Lisboa por falta de conseguirem as moradias públicas construídas pelo governo para as famílias em situação de 
vulnerabilidade socioeconômica que degradou o bem-estar coletivo da comunidade negra comovida pelo desemprego e das barreiras que se encontram em obter a nacionalidade portuguesa e o emprego (TELES, 2020).

Desta maneira, essa influência histórica colonial até então reforça a rejeição da aparência das pessoas negras com Humanos em que estabelece quem tem mais privilégios de viver mais do que o Outro, isso é a essência da colonização de desumanizar e controlar todos os povos não europeus. Em que a soberania máxima consiste em grande parte "no poder e na capacidade de ditar quem pode viver e quem deve morrer" (MBEMBE, 2016).

Nesta mesma linha de raciocínio se percebe que há desvalorização da morte dos negros, são aqueles considerados como incivilizados e ditos de Outros desviados do padrão da cultura Ocidental encarada como a referência universal. Por esta razão que é entendido que o racismo com suas várias formas de expressão que se vê sempre em muitas sociedades de hoje, está ligada com a história da colonização destas nações que continuam exaltando a superioridade racial branca europeia em relação aos povos africanos antes colonizados que as suas vidas não tem valor na visão das narrativas do racismo sistêmico presente nessas nações.

Sobre a diferença entre o multicultural e multiculturalismo HALL \& SOVIK (2003, p.52) defendem que:

\footnotetext{
Multicultural é um termo qualificativo. Descreve as características sociais e os problemas de governabilidade apresentados por qualquer sociedade na qual diferentes comunidades culturais convivem e tentam construir uma vida em comum, ao mesmo tempo em que retêm algo de sua identidade "original". Em contrapartida, o termo "multiculturalismo" é substantivo. Refere-se às estratégias e políticas adotadas para governar ou administrar problemas de diversidade e multiplicidade gerados pelas sociedades multiculturais. E usualmente utilizado no singular, significando a filosofia específica ou a doutrina que sustenta as estratégias multiculturais.
}

Nesta essência, vê-se que a primeira retrata as particularidades sociais e as questões da governança demonstradas por cada sociedade em que se nota o fortalecimento da unidade e da interação entre diferentes grupos de pessoas com culturas distintas mas que buscam conviver na harmonia e tentam criar laços de convivência social em coletivo. Ao passo que a segunda trata-se de planos e políticas usadas para governar. Aliás, representa a coexistência de inúmeras culturas em um território ou país. De certa maneira pode estimular a assimilação cultural dos que sofrem preconceito racial e que são influenciados a 
fazerem escolhas e assumir os instrumentos hegemônicos e saírem em situação em que se encontram (etnicidade).

Por outro lado, empenhar-se para ser um cidadão europeu e ao mesmo tempo africano precisa de algumas formas particulares de dupla consciência. Ao colocar isso não significa que ao apropriar-se dessas duas identidades incompletas esvazia as formas da subjetividade dos sujeitos. Todavia, em que as narrativas racista, nacionalista ou de caráter etnicamente absolutista instrumentalizam as políticas que até parece que essas identidades são reciprocamente pessoais, por esta razão que apropriar-se o espaço dessas identidades passa a ser entendido como uma ação desafiadora. Diante desse cenário, nota-se que:

Os negros ingleses contemporâneos, como os anglo-africanos de gerações anteriores e, talvez, como todos os negros no Ocidente, permanecem entre (pelo menos) dais grandes grupos culturais, que têm se transformado ao longo da marcha do mundo moderno que os formou e assumiu novas configurações. No momento, eles permanecem simbioticamente fechados em urna relação antagónica demarcada pelo simbolismo de cores que se soma ao poder cultural explícito de sua dinâmica maniqueísta central - preto e branco. Essas cores sustentam urna retórica especial que passou a ser associada a um jargão de nacionalidade e filiação nacional, bem como aos jargões de "raca" e identidade étnica (GILROY, 200I, p. 34).

Apesar de grande partes dos assuntos sobre as identidades foram desprezadas pelas

recentes discussões acerca da modernidade e seus insatisfeitos, por esta ocasião que essas concepções acerca da "nacionalidade, etnia, autenticidade e integridade cultural" são fatos exclusivamente modernos com consequências profundas para a crítica das formações culturais e a história cultural.

De certa maneira, seguindo o raciocínio de Bethencourt (2015, p. 80), nota-se que:

As feições estereotipadas atribuídas ao africano negro são as únicas identificáveis: cabelo crespo, lábios grossos e nariz largo. Aparentemente, as outras três cabeças representariam os tipos nórdico, mediterrânico e asiático. Essa hipótese inspira-se em imagens dos livros iluminados bizantinos e europeus ocidentais - em especial os manuscritos que descrevem as conquistas de Alexandre, as crônicas das Cruzadas e a Chronologia Magna - em que se representavam diferentes tipos de cabeça e cor da pele.

As representações estereotipadas dos povos africanos foram averiguadas durante o século XV com a colonização europeia em África e no século XIX na Ásia. Diante disso, o mundo clássico não tinha essa fragmentação assentada entre diferentes tipologias humanas, não obstante passou a experimentar essa classificação após a oposição entre distintos povos que influenciou na divisão entre leste e oeste criada pelos gregos para a divisão entre norte e sul dos romanos. Nesta separação, de certa maneira, tinha lugar para 
os povos asiáticos e assim como os africanos negros que foram levados para o mediterrâneo no contínuo trânsito do mercado escravagista.

\section{O reconhecimento da presença da população africana e sua diáspora em Portugal}

Para Henriques (2019), se o reconhecimento das populações africanas que estão fora do continente africano torna uma questão complexa, então isso requer o conhecimento profundo dos acontecimentos do passado colonial em África e sobre o processo da escravidão em que Portugal e outros países participaram ativamente no comércio transatlântico que arrancou as pessoas em África para a Europa e Américas mediante diferentes produtos oferecidos em troca de seres humanos transformados em mercadorias. Por isso que, hoje, é necessário reconhecer a colaboração deste povo na construção da sociedade portuguesa e não rejeitá-lo como Outro.

Nesta lógica, compreende-se que a presença Africana em Portugal não é por vontade própria, todavia este povo foi escravizado e retirado em diferentes países colonizados por Portugal no decorrer do século XV e que de certa forma forçou a vinda de muitos homens e mulheres africanos colocados na sociedade portuguesa na condição de "escravizados". Em vista disso, é entendida que existe ampla ausência do conhecimento da história real da chegada da população negra africana nesse país e em outros países do mundo onde foram levados à força como pessoas sem valor. O que merecem não é a rejeição física e social, mas o respeito mútuo.

A repercussão da economia e da presença dos escravizados e os seus descendentes em Portugal entre a segunda metade do século XV e o final do Antigo Regime nunca foi investigado. Assim, não se conhecia muito sobre o processo do abastecimento no mercado.

\footnotetext{
De facto, uma das características pouco conhecida do modo de abastecimento do mercado de escravos continental entre o século XV e 176r, é o grande número de entradas a título individual, através da maior parte dos navios de volta da Índia, da África oriental, de Angola e S. Tomé, do Golfo de Guiné, de Cacheu e de Cabo Verde e do Brasil. Provas não faltam. É a razão pela qual encontramos em muitos documentos do início do séc. XVII escravos de Moçambique que nessa altura não eram objecto do tráfico Atlântico. Encontramos igualmente durante este período um número bastante significativo de escravos asiáticos, genericamente designados como Índios (DIDIER LAHON, 2004, p. 74).
}

As diferentes entregas que se faziam dos escravizados provenientes desses países mencionados acima, muitos eram entregues por seus distintos compradores que entre eles destacam-se os padres de diferentes igrejas que tinham privilégios no que toca com 
descontos alfandegários quando compravam as pessoas escravizadas. Tinham benefícios totais ou parciais quando o escravizado era oferecido a título de esmola para esses sacerdotes. Um desses religiosos seu nome aparecia apenas uma vez, à medida que a maior parte deles possuem mais escravizados que os documentos sempre diziam de pedidos.

De outro lado, os povos africanos foram perseguidos, escravizados, oprimidos e transportados da África para Europa e a Américas no decorrer do período da escravidão. Nesta época os africanos e os seus descendentes são transformados em objetos de exploração particularmente em Portugal. Na sociedade portuguesa, vê-se a estigmatização dos corpos negros olhados como exóticos assentado no preconceito racial e da invisibilização das suas contribuições na formação desta sociedade entendida aqui como desconhecimento da história dos africanos e dos seus descendentes. Com a expansão do catolicismo em África, os africanos levados para Portugal, de grosso modo, eram educados para assimilação da cultura ocidental.

\begin{abstract}
Nos primeiros séculos de contatos, inúmeros africanos foram levados a Portugal para serem instruídos na fé, na cultura e nas línguas ocidentais. Alguns desembarcaram em Lisboa como homens livres, eram representantes da corte do Mani Congo, embaixadores, parentes da família real. Destes, alguns poucos se tornaram intérpretes (então chamados "línguas"), catequistas e sacerdotes. Por outro lado, o empenho dos soberanos e religiosos portugueses na formação de um clero indígena indica uma postura "mais cordata", tendo em vista o preconceito característico das relações dos europeus com africanos a partir do estabelecimento do comércio escravista em larga escala. Nesse sentido, as categorias de identificação utilizadas nos diferentes períodos revelam sistemas diversos de classificação, organização e, portanto, de percepção do africano (REGINALDO, 2009, p. 29I).
\end{abstract}

É notado que nos dias de hoje a historiografia portuguesa conseguiu se alforriar das dominações do regime salazarista e fascista que governava o país na época remota em que presenciava-se mais o racismo no "Reino de Portugal", silenciamento da escravidão e também se libertou de uma certa tendência "colonialista" no que diz respeito a interpretação da história africana e é preciso fazer a "reparação histórica" porque há uma ferida a ser curada por motivos das consequências deixadas pelo colonialismo na África e a reprodução de várias formas de discriminação racial em Portugal contra a população negra.

Seguindo mesmo raciocínio Martins (2019), ajuda-nos a compreender e a analisar melhor distintas informações relacionadas a presença do grande número da população africana em Portugal através da consequência do tráfico das pessoas escravizadas começado no século XV. Ainda assim, é entendido que, a historiografia portuguesa, por 
diferentes motivos, que de certa maneira abrange a continuidade de um defensor "lusotropicalista" na observação do passado colonial em que demorou em dar a merecida relevância ao tema da escravatura.

Com base nisso, é notada neste caso que há sim "uma presença silenciosa" e da falta de acesso a enormes experiências das mulheres e homens negros que a muitos séculos foram levados de África para serem escravizados na sociedade portuguesa na qual fazem parte na formação da nação, embora não são reconhecidos suas contribuições. Essa presença africana em Portugal tem iniciado a partir dos meados de século XV e intensificou-se mais no século XVI onde estima-se ıo\% de negros escravizados em Lisboa e Algarve. Nessa época, estes eram submetidos ao "trabalho escravo" e considerados várias vezes como "negros de ganhos".

\section{CONSIDERAÇÕES FINAIS}

Em conclusão, é notável que atualmente a colonização continua de outras formas, uma delas é a assimilação linguística, cultural, progressiva etc. De certa forma, envolve a dependência de alguns países africanos que sofriam a dominação do império colonial em vários âmbitos e colocando os mesmos na dependência. Pode-se dizer que a colonização é a principal responsável pela reprodução das desigualdades raciais em Portugal e caracterizando a posição social de cada grupo nessa sociedade. Esta problemática influencia no racismo estrutural vivenciado em Lisboa, por afrodescendentes e africanos nos bairros periféricos e não somente.

Como consequência disso, esse racismo acaba marginalizando os alunos que frequentam as escolas portuguesas onde as histórias da resistência dos povos africanos contra a dominação colonial eram narradas de forma distorcida e às vezes de forma irreal mediante o preconceito que tem acerca desse povo. No ensino português, a História de África suas referências culturais dos países em que esses alunos os seus pais são de origem são poucas abordadas na aula pelos professores, isso demonstra a desvalorização da história africana e o não reconhecimento da presença desse povo na sociedade portuguesa por causa do racismo enraizado em Portugal.

É interessante frisar que a presença da população africana em Lisboa/Portugal não foi somente por motivos da escravidão, não obstante pela imigração dos homens e 
mulheres nos anos de 1960 predominantemente originários de diferentes países africanos sobretudo dos PALOP colonizados por Portugal, escravizados e explorados no decorrer da era da invasão colonial. Aliás, essas nações africanas foram destruídas as suas formas de organização e a desintegração do povo. Após esse período com a independência desses países a imigração intensificou mais em 1970-1980 depois da emancipação desses territórios colonizados.

\section{REFERÊNCIAS BIBLIOGRÁFICAS}

ALMEIDA, Silvio Luiz de Racismo estrutural / Silvio Luiz de Almeida. -- São Paulo: Sueli Carneiro; Pólen, 2019. 264 p. (Feminismos Plurais / coordenação de Djamila Ribeiro). ISBN: 978-85-98349-74-9.

BETHENCOURT, Francisco. Racismos: das Cruzadas ao século XX. Tradução Luís Oliveira Santos, João Quina Edições. I. ed. São Paulo: Companhia das Letras, 2015.

GILROY, Paul, 1956-G588a. O Atlântico negro: modernidade e dupla consciência I Paul Gilroy; tradução de Cid Knipel Moreira. - São Paulo: Ed. 34; Rio de janeiro: Uníversidade Candido Mendes, Centro de Estudos Afro-Asiáticos, 20oI.

HALL, Stuart. Da diáspora: Identidades e mediações culturais. Organização Liv Sovik; Tradução Adelaine La Guardia Resende ... let all. - Belo Horizonte: Editora UFMG; Brasília: Representação da UNESCO no Brasil, 2003. 4M p. (Humanitas).

HENRIQUES, Isabel Castro. (Livro, 2019). A presença africana em Portugal, uma história secular: preconceito, integração, reconhecimento (Séculos XV-XIX).

LAHON, Didier. O escravo africano na vida económica e social portuguesa do antigo regime. Africana Studia, $N^{\circ}$ 7. 2004. Edição da Faculdade de Letras da Universidade do Porto pp 73-ıoo.

MARTINS, Bruno Sena. Os Negros em Portugal. Boletim Memórias, n. 53, pág. I-4, 2019.

MBEMBE, A. Necropolítica. Arte \& Ensaios, v. 2, n. 32, p. 123-151, 2016. Disponível em: https://revistas.ufrj.br/index.php/ae/article/view/8993/7169. Acesso em: I8 dezembro de 2021.

MENESES, M. P. (2016). A questão negra entre continentes: possibilidades de tradução intercultural a partir das práticas de luta?. Sociologias, 18, 176-206.

MUNANGA, K. (2004). Uma abordagem conceitual das noções de raça, racismo, identidade e etnia, p.I-I7.

MUNANGA, K. Negritude: usos e sentidos. São Paulo: Editora Ática. Série Princípios. $2^{\underline{a}}$ edição. 88 páginas. Ano da edição: 1988. 
RAPOSO, Otávio., Alves, Ana Rita., Varela, Pedro., e Roldão, Cristina. « Negro drama. Racismo, segregação e violência policial nas periferias de Lisboa », Revista Crítica de Ciências Sociais [Online], II9 | 2019, colocado online no dia o6 agosto 2019, criado a o8 agosto 2019. URL: http://journals.openedition.org/rccs/8937; DOI: 10.400o/rccs.8937.

REGINALDO, Lucilene. " África em Portugal": devoções, irmandades e escravidão no Reino de Portugal, século XVIII. História (São Paulo), v. 28, p. 289-319, 2009. 